J Res Adv Dent 2021;12:2:1-4.

\title{
Assessment of Distribution of Root Canal Sealer Distribution in Obturated Root Canal: A Comparative Study
}

\author{
Mubin Kutubuddin Mulla ${ }^{*}$ \\ ${ }^{1}$ Senior Lecturer, Department of Conservative Dentistry and Endodontics, Vasantdada Patil Dental College and Hospital, Kavalapur, Sangli, \\ Maharashtra, India.
}

\section{ABSTRACT}

Background: The strength of endodontically treated teeth depends on the remaining amount of tooth structure after canal preparation. Epoxy resin sealers like AH Plus was found to bond better to the core obturation material and root dentine. Hence, the present study was conducted with the aim of assessing the efficacy of root canal sealers in obturated root canals.

Materials \& methods: A total of 30 freshly extracted mandibular first premolars were collected and enrolled. Decoronation of all the specimens was done. Random division of all the samples was done in three study groups with ten specimens in each group as follows: Group 1: AH Plus sealer, Group 2: Tubliseal sealer, and Group 3: FUJI - 1 sealer. Obturation was carried out using the single-cone technique. Stereoscopic examination of the internal aspects of the sealer coated canals was done, followed by a calculation of the total percentage of the sealer-coated perimeter of the canal.

Results: Mean percentage of the sealer coated perimeter of the canal among group 1 specimens, group 2 specimens and group 3 specimens was 95.45\%, 98.28\% and 91.11\%, respectively. While analyzing statistically, it was seen that the highest percentage of sealer coated perimeter was found to be of Tubliseal and lowest for FUJI-1, the results of which were found to be statistically significant.

Conclusion: Highest percentage of sealer coated perimeter was found to be of Tubliseal and lowest for FUJI-1.

Keywords: Root canal sealer, Obturated root canal.

\section{INTRODUCTION}

The strength of endodontically treated teeth depends on the remaining amount of tooth structure after canal preparation. The factors affecting root fracture after endodontic therapy is over instrumentation, dehydration of dentine after endodontic therapy, and also uncontrolled pressure during obturation. All of these factors cumulatively and in addition to occlusal load increase the possibility of a root fracture. Furthermore, synergetic actions of intracanal irrigants and medicaments may also influence the physical and mechanical properties of the root dentine, which leads to failure or fracture of endodontically treated teeth. ${ }^{1-3}$ Epoxy resin sealers like AH Plus was found to bond better to the core obturation material and root dentine. They have the advantages such as less shrinkage, high radio-opacity, low solubility, better periapical repair and biocompatibility. Studies have evaluated the success of root canal treatment, the incidence of pain and healing ability and many other aspects of the root canal sealers both in vivo and in vitro.4- 6 Hence; the present study was conducted with the aim of assessing the efficacy of root canal sealers in obturated root canals.

Received: Jan. 3, 2021: Accepted: Feb. 12, 2021

*Correspondence Dr. Mubin Kutubuddin Mulla.

Department of Conservative Dentistry and Endodontics, Vasantdada Patil Dental College and Hospital, Sangli, Maharashtra, India.

Email: mubinkmulla@gmail.com

doi: https://doi.org/10.53064/jrad.2021.12.2.01

Copyright (C)2021 
$\mathrm{JRAD}$

The present study was conducted with the aim of assessing the efficacy of root canal sealers in obturated root canals. A total of 30 freshly extracted mandibular first premolars were collected and enrolled. Decoronation of all the specimens was done. Enlargement of all the specimens was done up to their working length using $\mathrm{K}$ files. Sodium hypochlorite solution and normal saline solutions were used for carrying out the root canal irrigation process. Removal of smear layer was done using Ethylenediaminetetraacetic acid (EDTA) solution for one minute. Random division of all the samples was done in three study groups with ten specimens in each group as follows:

Group 1: AH Plus sealer,

Group 2: Tubliseal sealer, and

Group 3: FUJI - 1 sealer

Obturation was carried out using the single-cone technique.

Storing of all the tooth specimens was done in $100 \%$ humidity at $37^{\circ} \mathrm{C}$ for seven days. After incubation, the teeth were sectioned horizontally at $3 \mathrm{~mm}$ from the apex with a diamond disk. Stereoscopic examination of the internal aspects of the sealer coated canals was done, followed by a calculation of the total percentage of the sealercoated perimeter of the canal. All the results were recorded and analyzed by SPSS software.

\section{RESULTS}

The mean percentage of the sealer coated perimeter of the canal among group 1 specimens, group 2 specimens and group 3 specimens was 95.45\%, $98.28 \%$ and $91.11 \%$, respectively, as shown in Table 1. While analyzing statistically, it was seen that the highest percentage of sealer coated perimeter was found to be of Tubliseal and lowest for FUJI-1, the results of which were found to be statistically significant as shown in Table 2.

\section{DISCUSSION}

The goal of root canal therapy is to remove and prevent apical periodontitis. To achieve this goal, complete removal of bacteria from the canal is important, as is the choice of filling material. Since gutta-percha was introduced to dentistry as a root
Mulla MK et al.

canal filling material in the mid-19th century, no significant advancements have been made over the past 170 years except for the introduction of silver cones. Instead, developments in root canal filling materials have focused on the chemical and physical properties of the sealer..$^{5-8}$

Table 1: Percentage of sealer-coated perimeter.

\begin{tabular}{|l|l|l|l|}
\hline $\begin{array}{l}\text { Percentage of the sealer- } \\
\text { coated perimeter }\end{array}$ & Group & Group & Group \\
\hline Mean & 1 & 2 & 3 \\
\hline SD & 95.45 & 98.28 & 91.11 \\
\hline
\end{tabular}

Table 2: Comparison of percentage of sealer-coated perimeter.

\begin{tabular}{|l|l|}
\hline Group comparison & p- value \\
\hline Group 1 Versus Group 2 & $0.0 *^{*}$ \\
\hline Group 1 Versus Group 3 & $0.01^{*}$ \\
\hline Group 2 Versus Group 3 & $0.01^{*}$ \\
\hline *: Significant & \\
\hline
\end{tabular}

Root canal sealers seal off of the root canal system, entombing the remaining bacteria and filling irregularities in the prepared canal. A root canal sealer should display appropriate physicochemical and biological properties. Grossmann suggested that excellent sealing ability, dimensional stability, slow setting time, insolubility, and biocompatibility are required for an ideal root canal sealer. Since the initial development of root canal sealers in the early 20th century, various root canal sealers have been developed to more adequately meet those requirements. ${ }^{7-} 10$ Hence, the present study was conducted with the aim of assessing the efficacy of root canal sealers in obturated root canals.

In the present study, the mean percentage of the sealer coated perimeter of the canal among group 1 specimens, group 2 specimens and group 3 specimens was 95.45\%, 98.28\% and 91.11\%, respectively. Setya G et al. compared sealer distribution in root canal using three different sealers with three different obturation techniques. AH, plus, Fuji-1, Tubliseal Extended Working Time (EWT) was placed into the prepared root canals of 90 maxillary central incisors using a lentulospiral. Thereafter, the canals were obturated using three different gutta-percha root filling techniques (single cone, lateral condensation, vertical condensation). Horizontal sectioning was carried out at $3 \mathrm{~mm}$ and 6 


\section{JRAD \\ Journal of Research and \\ Advancement in Dentistry}

$\mathrm{mm}$ from the apex with a diamond disk. The two specimens thus obtained were examined for sealer distribution using a stereomicroscope, and the percentage of sealer coating the perimeter (PSCP) was calculated using a digital imaging system. A significant difference existed in the mean PSCP values of three different sealers $(P<0.000)$, where Tubliseal (EWT) had the highest PSCP values followed by the AH plus and Fuji-1. Also, between techniques, differences were observed $(\mathrm{P}<0.00)$, where a single cone technique had the highest mean values followed by lateral condensation and vertical condensation. Between the $3 \mathrm{~mm}$ and $6 \mathrm{~mm}$ sections, a non-significant difference was observed $(\mathrm{P}<0.945)$. Tubliseal EWT showed the highest PSCP value, and the Single cone technique showed the higher PSCP value than the lateral and vertical condensation technique at $3 \mathrm{~mm}$ and $6 \mathrm{~mm}$ sections. $^{10} \mathrm{M} \quad \mathrm{K} \quad \mathrm{Wu}$ et al. observed sealer distribution in root canals filled by different root filling techniques. AH26 $(0.05 \mathrm{~mL})$ dyed with carbon black powder was placed into the prepared root canals of maxillary central incisors using a lentulospiral. At $6 \mathrm{~mm}$ from the apex, however, the PSCP was significantly higher after lateral condensation than after vertical condensation $(\mathrm{P}<$ 0.05). At both levels, the PSCP was significantly higher after a single cone (no condensation) than after the other two condensation techniques $(\mathrm{P}<$ 0.0001). The sealer may be removed from the canal wall by the condensation procedures. ${ }^{11}$

In the present study, while analyzing statistically, it was seen that the highest percentage of sealer coated perimeter was found to be of Tubliseal and lowest for FUJI-1, the results of which were found to be statistically significant. Huang $\mathrm{Y}$ et al. analyzed the ability of multiple compounds to seal the dental tubules using scanning electron microscopy (SEM) and micro-computed tomography (micro-CT). Twenty-four single-root human mandibular premolars were selected and instrumented with nickel-titanium rotary file, and the final file size was \#40/06. They were then randomly allocated into two groups, and all samples were filled with single cone gutta-percha (\#40/06) and one of the tested sealers (AH Plus and EndoSequence BC sealers). All specimens were scanned using micro-CT, and then three from each group were randomly selected for SEM analysis. No significant difference was observed for those two parameters between $\mathrm{AH}$
Mulla MK et al.

Plus and EndoSequence BC sealers in any of the three sections ( $p>0.05)$, whereas they were larger in the apical section when the AH Plus sealer was used. By using the single cone technique, neither EndoSequence nor AH Plus pro-vides a porosityfree root canal filling. ${ }^{12,13}$

\section{CONCLUSION}

The highest percentage of sealer coated perimeter was found to be Tubliseal and lowest for FUJI-1.

\section{CONFLICTS OF INTEREST}

The authors declare they have no potential conflict of interests regarding this article.

\section{REFERENCES}

1. Sarkar NK, Caicedo R, Ritwik P, Moiseyeva R, Kawashima I. Physicochemical basis of the biologic properties of mineral trioxide aggregate. J Endod. 2005;31:97-100.

2. Reyes-Carmona JF, Felippe MS, Felippe WT. Biomineralization ability and interaction of mineral trioxide aggregate and white Portland cement with dentin in a phosphate-containing fluid. J Endod. 2009;35:731-6.Gani O. Quality of apical seal in curved canal using three types of spreaders. J Endod. 2002;28:351-4.

3. Spanberg LS, Haapasalo M. Rationale and efficacy of root canal medicaments and root filling materials with emphasis on treatment outcome. Endod Topics. 2002;2:35-58.

4. Shantiaee Y, Dianat O, Janani A, Kolahi Ahari G. In vitro evaluation of the antibacterial activity of three root canal sealers. Iran Endod J. 2010;5:1-5.

5. Khedmat S, Sedaghati M. Comparison of the tensile strength of four root canal sealers. J Dent (Tehran) 2006;3:1-5

6. McMichen FR, Pearson G, Rahbaran S, Gulabivala K. A comparative study of selected physical properties of five root-canal sealers. Int Endod J. 2003;36:629-35.

7. Luccy CT, Weller RN, Kulild JC. An evaluation of the apical seal produced by lateral and warm 
lateral condensation techniques. J Endod. 1990;16:170-2.

8. Dalat DM, Spångberg LS. Comparison of apical leakage in root canals obturated with various gutta percha techniques using a dye vacuum tracing method. J Endod. 1994;20:315-9.

9. Greene HA, Wong M, Ingram TA. Comparison of thermoplasticized injectable gutta-percha obturation technique. J Endod. 1991;17:260-4.

10. Setya G, Nagpal A, Kumar S, Ingle NA. Comparison of root canal sealer distribution in obturated root canal: An in-vitro study. J Int Soc Prev Community Dent. 2014;4(3):193-197. doi:10.4103/2231-0762.142028
11. M K Wu 1, A R Ozok, P R Wesselink. Sealer distribution in root canals obturated by three techniques. Int Endod J. 2000 Jul;33(4):340-5.

12. Huang Y, Orhan $\mathrm{K}$, Celikten B, Orhan AI, Tufenkci P, Sevimay S. Evaluation of the sealing ability of different root canal sealers: a combined SEM and micro-CT study. J Appl Oral Sci. 2018;26:e20160584.

13. Shah MM, Parekh VV, Patel NJ, Dodiya PV, Chauhan DH. New insight into the role of electronic apex locators in detecting simulated horizontal root fractures: An in vitro study. Adv Hum Biol 2019;9:32-6. 